\title{
BIOAUMENTAÇÃO PARA DEGRADAÇÃO DE EFLUENTES DO PROCESSAMENTO DA CASTANHA DE CAJU
}

\author{
C. E. M. Jerônimo', H. G. Fernandes², H. N. S. Melo² e J. F. Sousa ${ }^{2}$ \\ ${ }^{1}$ Universidade Potiguar. \\ ${ }^{2}$ Universidade Federal do R. G. do Norte - DEQ. \\ c_enrique@hotmail.com, hermano_eq@yahoo.com.br, henio@eq.ufrn.br e joao@eq.ufrn.br
}

Artigo submetido em fevereiro/2012 e aceito em julho/2012

\section{RESUMO}

O presente trabalho teve por objetivo avaliar a viabilidade técnica da aplicação de cepas específicas de microorganismos comerciais (bioaumentação) no tratamento de efluentes industriais. Para este caso específico utilizaram-se amostras oriundas do processo de beneficiamento da castanha de caju, um efluente oleoso e de difícil biodegradação. Foram analisadas as condições operacionais (presença de oxigênio e agitação mecânica), frente a eficiência de remoção dos constituintes orgânicos presentes nas amostras e os aspectos operacionais envolvidos. Observou-se que a aplicação da técnica aeróbia com agitação, se mostrou mais viável. Porém, estudos complementares se fazem necessários para aperfeiçoar tais condições operacionais, principalmente, para ajustar a relação substrato e matéria viva.

PALAVRAS-CHAVE: Bioacumulação, Efluente Agroindustrial e Processos Aeróbios.

\section{BIOACCUMULATION EFFLUENT DEGRADATION FOR THE PROCESSING OF CASHEW NUTS}

\section{ABSTRACT}

The present work had for objective to evaluate the viability technique of the application of cepas specific of commercial microorganisms (bioaccumulation) in the treatment of effluent industrials. For this in case that specific deriving samples of the process of improvement of the cashew chestnut had been used, effluent an oily one and of difficult biodegradation. For such, the operational conditions (presence of oxygen and agitation mechanics), the involved front the efficiency of removal of the organic constituent gifts in the samples and operational aspects had been analyzed. It was observed that the application of the aerobic technique with agitation, if showed viable. However, complementary studies if make necessary to optimize such operational conditions, mainly, to adjust to the relation substratum and alive substance.

KEY-WORDS: Bioaccumulation, Agroindustrial Effluents and Aerobic Process. 


\section{BIOAUMENTAÇÃO PARA DEGRADAÇÃO DE EFLUENTES DO PROCESSAMENTO DA CASTANHA DE CAJU}

\section{INTRODUÇÃO}

A disposição adequada dos esgotos e efluentes industriais é essencial para a proteção da saúde pública. Cerca de 50 diferentes tipos de infeç̧ões podem ser transmitidas de uma pessoa doente a outra sadia, envolvendo os dejetos humanos. Os esgotos podem contaminar a água, alimentos, utensílios domésticos e o solo, além de ser transportado por moscas e baratas, provocando novas infecções. Epidemias de febre tifóide, cólera, desinterias, hepatite infecciosa e inúmeros casos de verminoses são responsáveis por elevados índices de mortalidade em países em desenvolvimento. As crianças são as vítimas mais freqüentes (Von Sperling, 2005).

Outra importante razão para tratar os esgotos é a preservação do meio ambiente. As substâncias presentes nos esgotos exercem ação nociva nos corpos de água: a matéria orgânica pode ocasionar a exaustão do oxigênio dissolvido, com mortalidade de peixes e outros organismos aquáticos, escurecimento da água e aparecimento de maus odores; também é possível que detergentes presentes nos esgotos provoquem espumas em pontos de agitação da massa líquida, entre outros problemas (Von Sperling, 2002).

Assim, o presente trabalho teve por objetivo avaliar a viabilidade técnica da aplicação de cepas específicas de microorganismos comerciais (bioaumentação) no tratamento de efluente oriundo do beneficiamento da castanha de caju. Para este caso específico utilizaram-se amostras oriundas das etapas de lavagem e umidificação da castanha de caju, ou seja, um efluente oleoso e de difícil biodegradação. Para tal, foram analisadas as condições operacionais (presença de oxigênio e agitação mecânica), frente a eficiência de remoção dos constituintes orgânicos presentes nas amostras.

Segundo Atlas (1993), a Bioaumentação consiste na modificação do meio ambiente visando eliminar fatores limitantes ao crescimento e desenvolvimento dos microrganismos, incrementando, dessa forma, a biodegradação dos compostos orgânicos poluentes pela população nativa. Ele acrescenta que a bioaumentação junto com a tecnologia de inoculação de microrganismos externos (seeding) constituem as técnicas mais utilizadas na biorremediação (recuperação de áreas degradadas pela ação do homem).

Neste trabalho, a Bioaumentação será definida como a suplementação de microrganismos externos, principalmente bactérias, de ocorrência natural, não patogênicos nem alterados geneticamente, a sistemas de tratamento de resíduos orgânicos, com o objetivo de aumentar a eficiência dos processos biológicos e, conseqüentemente, melhorando as características do efluente final.

A tecnologia de Bioaumentação não é nova e já vem sendo praticada nos EUA desde os anos 60. No Brasil, a tecnologia teve maior incremento nos anos $90 \mathrm{com}$ a chegada ao país de empresas que comercializam aditivos bioquímicos com esta finalidade. A adição de microrganismos selecionados e multiplicados em laboratório a sistemas de tratamento de efluentes vem beneficiar todo esse processo porque a população nativa, normalmente formada por microrganismos presentes no efluente ou trazidos pela água da chuva, poeira, ventos ou mesmo inoculados de outra fonte - como esgoto sanitário, nem sempre são os mais efetivos na biodegradação dos compostos orgânicos, em função da relação de nutrientes (carbono, 
nitrogênio e fósforo), conforme descreve Jones (2012). É importante considerar também que os mesmos encontram-se no ambiente em homeostase, ou seja, em equilíbrio. Dentro desta população nativa, há microrganismos desejáveis, capazes de biodegradar os compostos orgânicos poluentes, e a população não-desejável, sem capacidade de biodegradação e que ainda compete com os primeiros por fatores de crescimento e oxigênio (Dors, 2006).

Quando uma alta população microbiana selecionada é adicionada para degradação de altas taxas orgânicas, como os produtos para bioaumentação, a homeostase se rompe, permitindo uma maior degradação dos compostos orgânicos poluentes pelos microrganismos introduzidos e pelos nativos, que estavam sendo impedidos de degradar em todo seu potencial, devido ao equilíbrio entre as populações presentes no meio.

Esta alteração na microbiota propicia melhora na qualidade final do efluente. Como a tendência natural é que os microrganismos nativos voltem a predominar, entrando novamente em equilíbrio, torna-se necessário a aplicação continuada dos aditivos bioquímicos para evitar que a eficiência na remoção da carga orgânica seja prejudicada e volte aos patamares anteriores à aplicação, conforme cita Albuquerque (2000).

Outra possibilidade de aplicação da bioaumentação ocorre nos casos em que a microbiota nativa, presente em um sistema e que vinha propiciando bons resultados na degradação dos compostos orgânicos, é eliminada ou diminuída devido ao choque de carga orgânica ou adição de produtos tóxicos, com a conseqüente redução na remoção da carga orgânica do efluente, ficando a natureza e a população sujeitas a focos de contaminação e poluição (Jones, 2012).

Diante desse quadro, o efluente oriundo do beneficiamento da castanha de caju, tem um papel importante, em especial no nordeste do Brasil, pela alta agressividade de sua composição fenólica e pelo montante de água consumida e efluente ao processo, necessitando de estudos para o desenvolvimento de técnicas eficientes, e, sobretudo, de baixo custo para mitigar os impactos ambientais provenientes desse segmento industrial. Logo, a bioaumentação, com produtos já comerciais, torna-se uma importante alternativa para tal cenário. Neste estudo, é feita uma análise da viabilidade do produto GorduraKlin ${ }^{\circledR}$ para tratamento de efluentes oleosos contaminados com o LCC (líquido da castanha de caju).

\section{MATERIAIS E MÉTODOS}

Os efluentes foram coletados em uma indústria de beneficiamento de castanha de caju, localizada no estado do Rio Grande do Norte - nordeste brasileiro, após a liberação para o sistema de tratamento físico da unidade. Os efluentes eram oriundos dos processos de lavagem e umidificação da castanha de caju. As amostras foram coletadas em temperatura ambiente, cerca de 34 으, em frascos de 3 litros. Os recipientes eram conservados em recipientes térmicos, durante o transporte, e acondicionados em refrigeradores com temperaturas controladas em torno de 4ํ․ A composição do efluente utilizado é apresentada conforme Tabela 1. 
Tabela 1: Caracterização do Efluente

\begin{tabular}{|c|c|c|c|}
\hline Parâmetros & Valor Médio & Unidade & Desvio Padrão \\
\hline DQO & 2200 & $\mathrm{mg} / \mathrm{L}$ & 38 \\
\hline DBO & 1800 & $\mathrm{mg} / \mathrm{L}$ & 56 \\
\hline ST & 1200 & $\mathrm{mg} / \mathrm{L}$ & 12 \\
\hline SV & 810 & $\mathrm{mg} / \mathrm{L}$ & 22 \\
\hline SF & 390 & $\mathrm{mg} / \mathrm{L}$ & 6 \\
\hline SS & 360 & $\mathrm{mg} / \mathrm{L}$ & 16 \\
\hline pH & 6,8 & - & 0,5 \\
\hline Fenóis & 90 & $\mathrm{mg} / \mathrm{L}$ & 6 \\
\hline $\begin{array}{c}\text { Nitrogênio } \\
\text { Amoniacal }\end{array}$ & 20 & $\mathrm{mg} / \mathrm{L}$ & 1,2 \\
\hline Nitrogênio Total & 42 & $\mathrm{mg} / \mathrm{L}$ & $\mathbf{2 , 6}$ \\
\hline Cloretos & 120 & $\mathrm{mg} / \mathrm{L}$ & 6,2 \\
\hline Nitrito & 12 & $\mathrm{mg} / \mathrm{L}$ & 1,1 \\
\hline Nitrato & 6 & $\mathrm{mg} / \mathrm{L}$ & $\mathbf{0 , 5}$ \\
\hline Turbidez & 318 & & \\
\hline & & & \\
\hline
\end{tabular}

Os ensaios de tratamento foram conduzidos com a adição de doses do aditivo Gorduraklin ${ }^{\circledR}$, conforme recomendação do fabricante, ou seja, cerca de $25 \mathrm{mg} / \mathrm{L}$. O aditivo é composto por enzimas e bactérias viáveis (p.ex. Pseudomonas aeruginosa LP602 e Anicetobacter calcoaceticus LP609), possui uma solubilidade em água moderada. É um produto que não polimeriza, tem uma aparência rosada, com odor semelhante a uma levedura, uma densidade de 0,6 a 0,8 e quando solubilizado tende a um pH de 6,0 a 8,0. Os microorganismos utilizados têm adaptação em meio aeróbio e anaeróbio.

Os efluentes foram acondicionados num reator agitado, de capacidade de $2,5 \mathrm{~L}$, dotado de um sistema de agitação mecânica e um soprador de ar, com vazão de $2 \mathrm{~L} / \mathrm{min}$. O esquema do equipamento utilizado é mostrado na Figura 1. O reator possibilita o processamento em um meio anaeróbio ou aeróbio pelo acionamento ou não do soprador. O que possibilitou o estudo da influência dos diferentes meios e misturas frente a operacionalidade do sistema.

O reator consiste de um recipiente hermeticamente fechado, isolado por válvulas para coleta de amostras, enclausurado com borrachas de vedação que não permite o contra-fluxo de ar do ambiente para o meio reacional. O equipamento é construído de vidro temperado de alta 
resistência e elementos de inox para injeção de ar. Ligando-se, ou não, o soprador estabelece-se a condição de operação do equipamento.

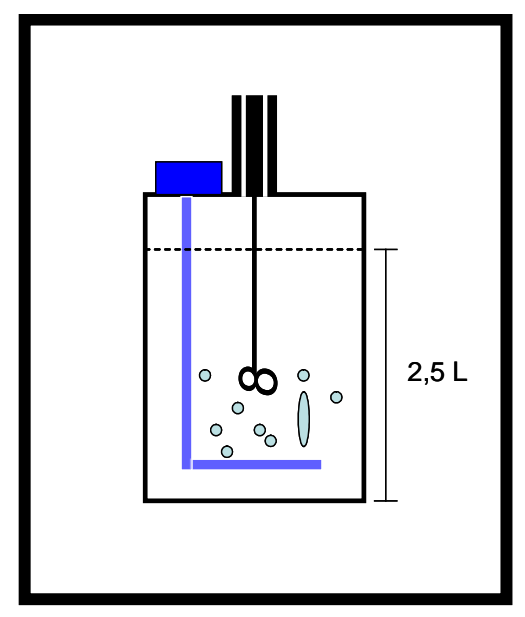

Figura 1: Esquema do reator biológico facultativo.

O monitoramento dos experimentos foi estabelecido com a medição da Demanda Química de Oxigênio (DQO), mediante a técnica de refluxo fechado para digestão, com determinação espectrofotométrica, em intervalos regulares de tempo. Além disso, a turbidez, o $\mathrm{pH}$ e a condutividade do sistema também foram registrados em intervalos regulares de tempo.

Os procedimentos analíticos seguiram as ações preconizadas em APHA (1998). As determinações analíticas foram realizados em quadruplicata, mediante a monitoração do $\mathrm{pH}$, Acidez, DQO, condutividade e turbidez, sendo os resultados apresentados referentes aos valores médios obtidos. As amostras foram colhidas em intervalos que variaram de 12 a 24 horas.

Os ensaios foram realizados no nível de concentração sugerido pelo fabricante para efluentes de mesmo nível de óleos e graxas, tendo-se testados a presença ou não do oxigênio.

$\mathrm{Na}$ etapa preliminar desse estudo, foram realizados alguns testes (em duplicata) para avaliar o comportamento dos microorganismos (com características facultativas), frente às condições ambientais do meio reacional, frente a fatores inerentes a disponibilidade de oxigênio e a fatores hidrodinâmicos. Para isso, três condições operacionais foram testadas, a saber: processo anaeróbio (ausência completa de oxigênio), processo aeróbio com mistura imperfeita (inserção de gás dissolvido, porém, a agitação do meio era feita unicamente pelo efeito da turbulência das bolhas de ar) e o processo aeróbio com mistura perfeita (onde a agitação era complementada, ao efeito das bolhas de ar, por hélices dispostas em sentido radial, movimentadas por meio mecânico).

Numa segunda etapa, os ensaios cinéticos foram ajustados a modelos matemáticos para identificação da ordem e parâmetros reacionais envolvidos. Os dados experimentais desses ensaios foram obtidos em triplicatas, obtidas em diferentes ensaios.

\section{RESULTADOS OBTIDOS}

Com base nos ensaios realizados foram tabulados e gerados os gráficos de desempenho dos experimentos. Na Figura 2, são apresentados os resultados para a variação do $\mathrm{pH}$ ao longo do 
processo de biodegradação. Nestes dados, observa-se que o processo de degradação natural, por meio do processo anaeróbio, é quase inexistente, já que a medida em que o tempo do processo é aumentado, os valores do $\mathrm{pH}$ do meio reacional, praticamente, se mantém invariáveis. Visto que segundo Von Sperling (2002), a reação anaeróbica tem na sua primeira fase a produção de ácidos graxos (acidogênese), que se torna um indício do avanço da degradação da matéria orgânica.

Para os processos aeróbios, ocorrem variações, principalmente originárias da quebra da matéria orgânica, bem mais pronunciada, a qual é evidenciada pela acidificação do meio, em um período transiente (até que o regime da fase lag do crescimento bacteriano seja substituído pelo regime exponencial), tendendo ao equilíbrio neutro em termos da concentração de íons $\mathrm{H}+\mathrm{O}$ efeito da agitação do meio não foi observado, tendo esses experimentos comportamento e ordem de grandeza análoga (Dors, 2006).

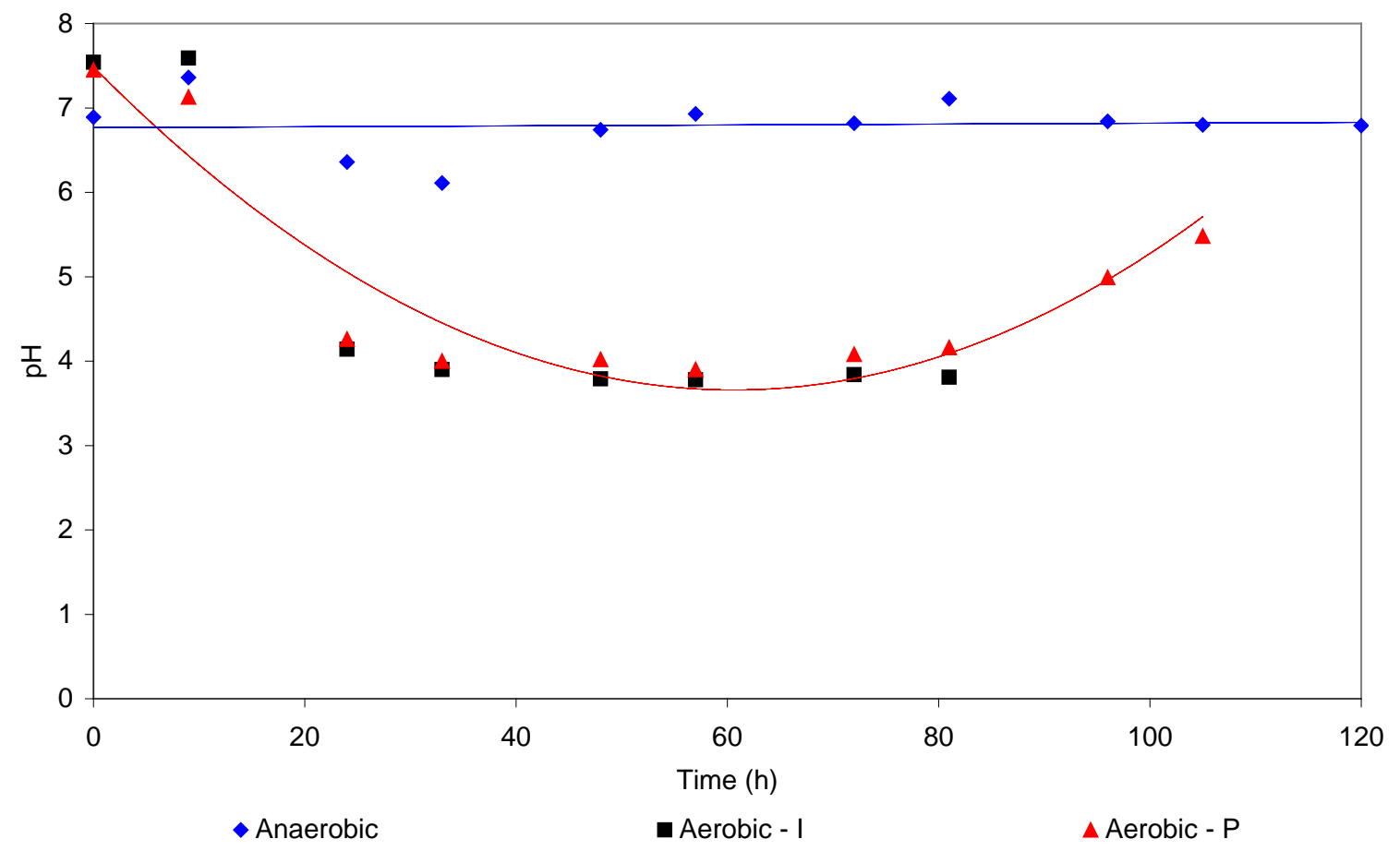

Figura 2: Variação do pH do efluente, inoculado com a cepa específica de (GORDURAKLIN ${ }^{\circledR}$ ), ao longo do processo de biodegradação, em diferentes condições operacionais, frente à disponibilidade de oxigênio e efeitos hidrodinâmicos.

A variação da condutividade elétrica do meio, como variável de monitoramento do processo de biodegradação, pode ser observada na Figura 3. Nos resultados obtidos observa-se uma redução desta propriedade, porém, em níveis pouco pronunciados. Esse efeito moderado pode ser resultado de uma combinação entre o aumento da concentração de sais e a redução dos componentes orgânicos (com a conversão em ácidos orgânicos), o que provavelmente reduz os coeficientes de solubilidade dos componentes que causam efeitos diretos na condução da eletricidade no meio. Esse efeito, é explicado por Von Sperling (2005), quando da quebra da matéria orgânica, em componentes ácidos, cujo outro incremento favorece a redução do pH entra no sistema, visto que o ar dissolvido eleva-se a níveis próximos da saturação, em cerca de 7$8 \mathrm{mg}$ de O2/L, e que consequentemente auxilia na dissociação do meio, pela presença em especial do gás carbônico, e posteriormente elevação da condutividade do meio. 


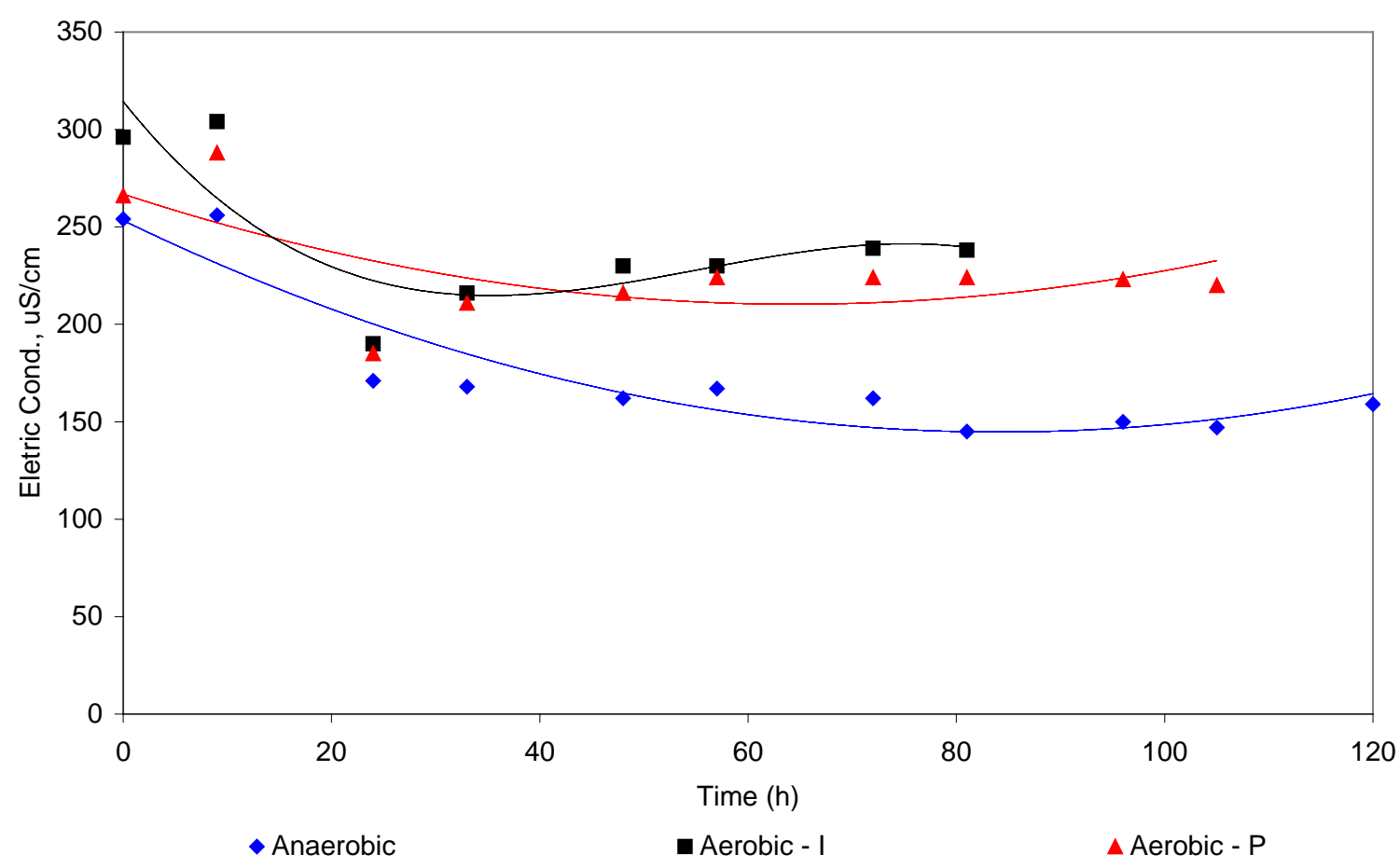

Figura 3: Variação da condutividade elétrica do efluente, inoculado com a cepa específica de (GORDURAKLIN ${ }^{\circledR}$ ), ao longo do processo de biodegradação, em diferentes condições operacionais, frente à disponibilidade de oxigênio e efeitos hidrodinâmicos.

Outra variável estudada foi a turbidez do meio, tendo-se os resultados representados pela Figura 4. Para os resultados obtidos, os comportamentos entre os processos foram distintos, os quais cabem uma discussão própria para cada caso, então temos:

Processo Anaeróbio: neste caso, os efeitos microbianos se direcionam para as reações anabólicas (crescimento celular), o que geram uma concentração menor de partículas coloidais no processo de conversão da matéria orgânica solúvel em matéria depurada. As partículas coloidais, geralmente, se apresentam suspensas no efluente, tendo um efeito direto no aumento da medição da turbidez. Neste caso, pela tendência à redução da matéria orgânica e a pouca conversão em biomassa (células mortas e vivas de microorganismos), tem-se um favorecimento a redução da turbidez do efluente. O que é evidenciado pelos dados experimentais obtidos, inclusive por uma tendência linear com baixa inclinação (quase nula), para redução desse parâmetro.

Processo Aeróbio com mistura incompleta: para o processo aeróbio, tem-se um efeito inverso ao anaeróbio, ou seja, as reações principais se direcionam a reprodução rápida e exponencial dos microorganismos presentes, ou melhor, para as reações catabólicas. Frente aos dados experimentais, observa-se um crescimento linear da turbidez com o tempo de processo, o que é efeito direto da degradação dos componentes orgânicos dissolvidos, e sua conversão em células microbianas, em suspensão. Devido aos níveis de conversão, para esse processo, atingir patamares consideráveis, na faixa estudada, pela ausência de um mecanismo de agitação satisfatória que favoreça a estabilização do meio, o efeito é sempre crescente, conforme relata Zanoto (2003) e Soares; Zaiat (2005). 
Processo Aeróbio com mistura completa: neste caso, com todos os efeitos negativos removidos, a tendência ao aumento da turbidez, pelas reações catabólicas, é evidenciado nas 20 primeiras horas de reação, tendo-se uma tendência a uma estabilização após 40 horas de processo num patamar mediano, porém, cerca de 3 vezes superior aos valores iniciais. 0 regime se torna estagnado, em termos de disponibilidade de nutrientes e número de organismos vivos, e o processo opera na faixa da curva de crescimento microbiano, descrita em WORLD HEALTH ORGANIZATION (1989).

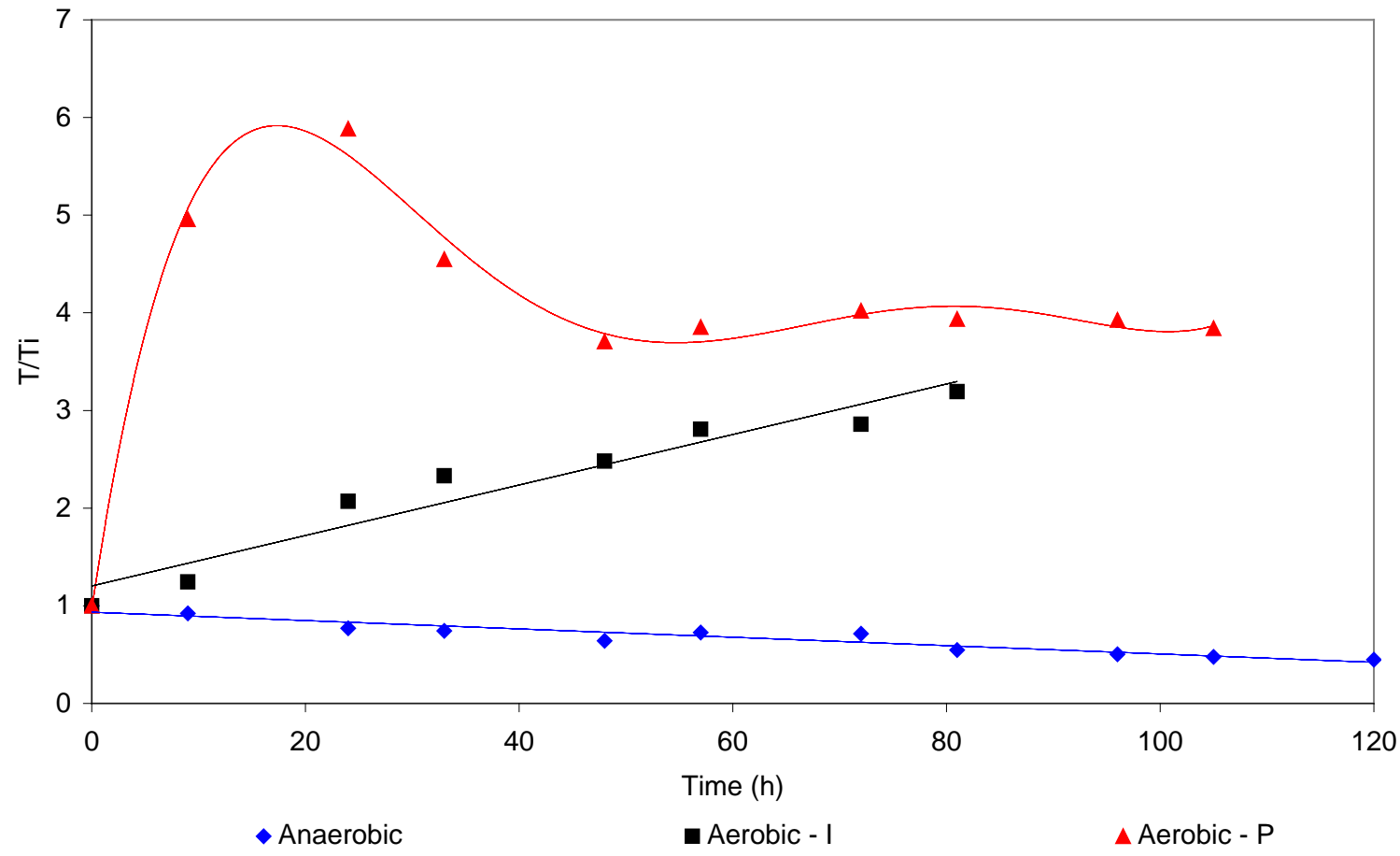

Figura 4: Variação da Turbidez do efluente, inoculado com a cepa específica de (GORDURAKLIN ${ }^{\circledR}$ ), ao longo do processo de biodegradação, em diferentes condições operacionais, frente à disponibilidade de oxigênio e efeitos hidrodinâmicos.

Por fim, o efeito principal para referenciar a qualidade dos processos analisados é mostrado na Figura 5, ou seja, a curva de decaimento da matéria orgânica quimicamente degradável, representada pela razão entre as concentrações da DQO pontual e a inicial. Tais resultados traduzem de uma forma mais contundente a eficiência de cada processo. Tendo-se, a comprovação de que a cepa especifica contida no produto comercial Gorduraklin ${ }^{\circledR}$, opera mais rapidamente em ambientes aeróbios e que a introdução da agitação mecânica, homogeneízam o meio, ofertando de forma mais distribuída os nutrientes para o consumo pelos microorganismos, não causando mortandade desnecessária. Além de tudo, observa-se, ainda, que a aplicabilidade destas cepas ao tratamento de efluentes contaminados com LCC (líquido da castanha de caju), torna-se uma alternativa viável, do ponto de vista técnico, com níveis de eficiência da ordem de 90\% de remoção. 


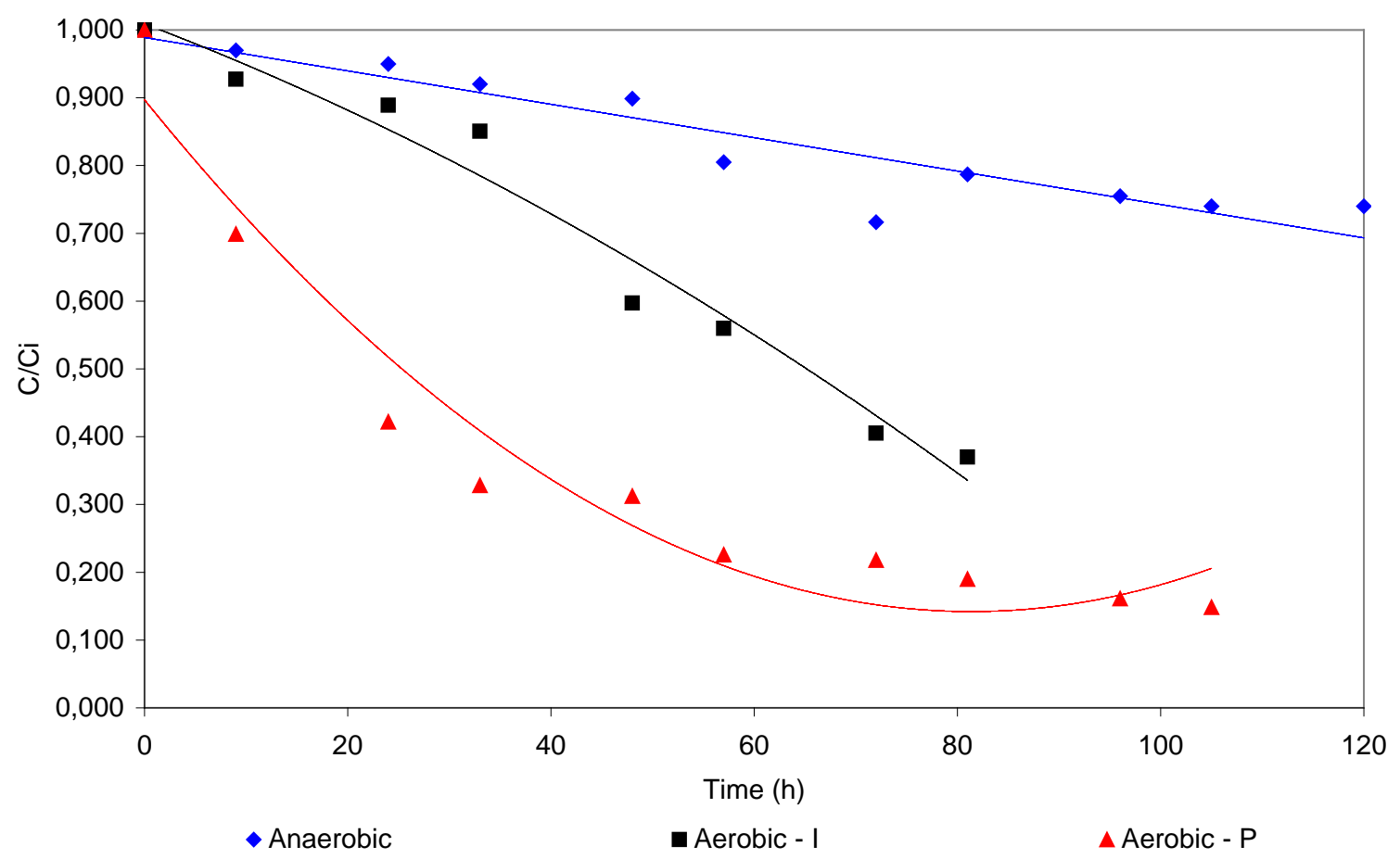

Figura 5: Variação do percentual médio de DQO remanescente do efluente, inoculado com a cepa específica de (GORDURAKLIN ${ }^{\circledR}$ ), ao longo do processo de biodegradação, em diferentes condições operacionais, frente à disponibilidade de oxigênio e efeitos hidrodinâmicos.

Para um melhor conhecimento dos fenômenos envolvidos, e para subsidiar parâmetros de projeto - mais consistentes e representativos aos fenômenos observados no processo; testaramse alguns modelos matemáticos, equações diferenciais de primeira e segunda ordem, para consolidar qual deles oferece um melhor emprego aos dados experimentais obtidos. Para isso, as equações foram desenvolvidas conceitualmente, gerando as equações base para o ajuste aos dados experimentais. Seqüencialmente, os dados foram plotados, com eixos definidos pelo formato das equações base, e ajustadas linearmente pela regressão de seus dados pelo método dos mínimos quadrados. Nas Figuras 6 e 7 são representados os ajustes obtidos, com seus respectivos coeficientes de correlação para os diferentes processos estudados. Os resultados não evidenciam uma ordem preponderante, dentre as estudadas, porém, pelos ótimos resultados obtidos (98\% de correlação) para o modelo de segunda ordem, para o experimento de melhor nível de controle e de quase ausência de interferentes externos. Neste trabalho será considerada, então, a $2^{a}$ ordem para a modelagem e estimativa dos parâmetros cinéticos de projeto, bem como, otimização das condições operacionais.

Um efeito anômalo pode ser observado no ajuste dos dados para a cinética de segunda ordem, onde o resultado para a reta ajustada no ensaio aeróbio sem agitação possui inclinação maior ao do ensaio com agitação, o que é plenamente aceitável na medida em que os ensaios sem agitação apresentaram erros significativos, entre os ensaios realizados nas mesmas condições operacionais, com valores percentuais superiores a $26 \%$. Enquanto, os ensaios com agitação apresentaram percentuais da ordem de $4 \%$. Daí, tal questão ter sido considerada para a escolha da ordem reacional.

Outro fator decisivo na escolha do modelo é o fato da heterogeneidade de componentes do meio, o que se analisado de forma ponderada, nos remete ao direcionamento para a segunda 
ordem. Resultados similares já foram obtidos, com tais considerações, por RIBEIRO et al (2001) para o desenvolvimento de modelos no tratamento anaeróbio de efluentes lácticos (com alto teor de óleos e graxas).

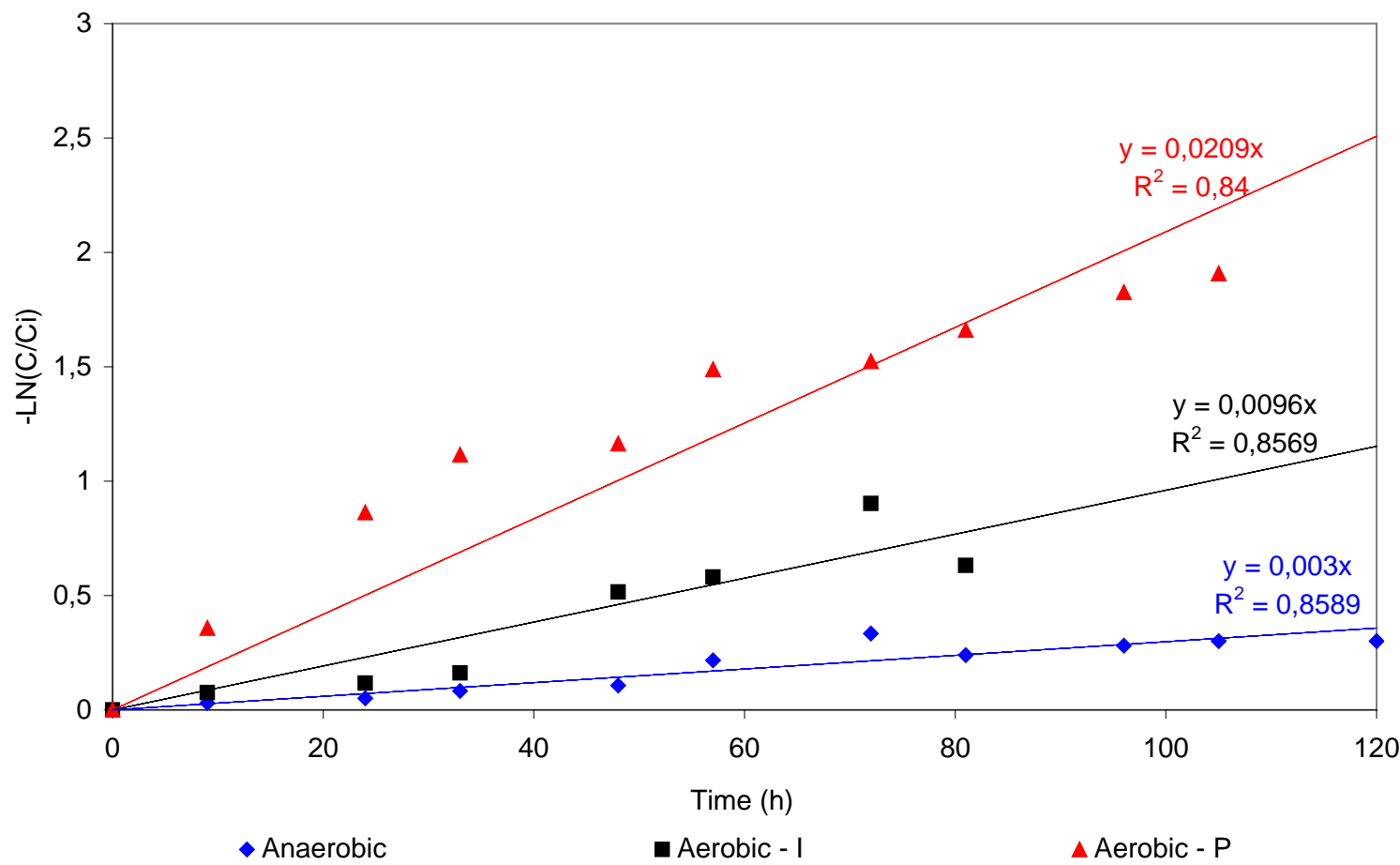

Figura 6: Ajuste linear de uma equação de primeira ordem para a cinética média de degradação da Demanda Química de Oxigênio (DQO) do efluente, inoculado com a cepa específica de (GORDURAKLIN ${ }^{\circledR}$ ), ao longo do processo de biodegradação, em diferentes condições operacionais, frente à disponibilidade de oxigênio e efeitos hidrodinâmicos.

Comparativamente, a ordem de grandeza obtida para o efluente contaminado com LCC frente a efluentes do beneficiamento do leite, descrito em Ribeiro (2001), tem-se valores na mesma ordem de grandeza, entretanto, para taxas de degradação maiores pelo efeito direcionado da biota microbiana utilizada.

Para um ajuste mais significativo dos parâmetros cinéticos, utilizou-se o critério da velocidade inicial, Heredia et al (2001), onde apenas os quatro pontos iniciais são levados em conta para a regressão linear dos dados experimentais. Para tal, o efeito comparativo pode ser observado na Figura 8. Os coeficientes da regressão são superiores a 94\%, o que atesta uma boa observância ao modelo elaborado. 


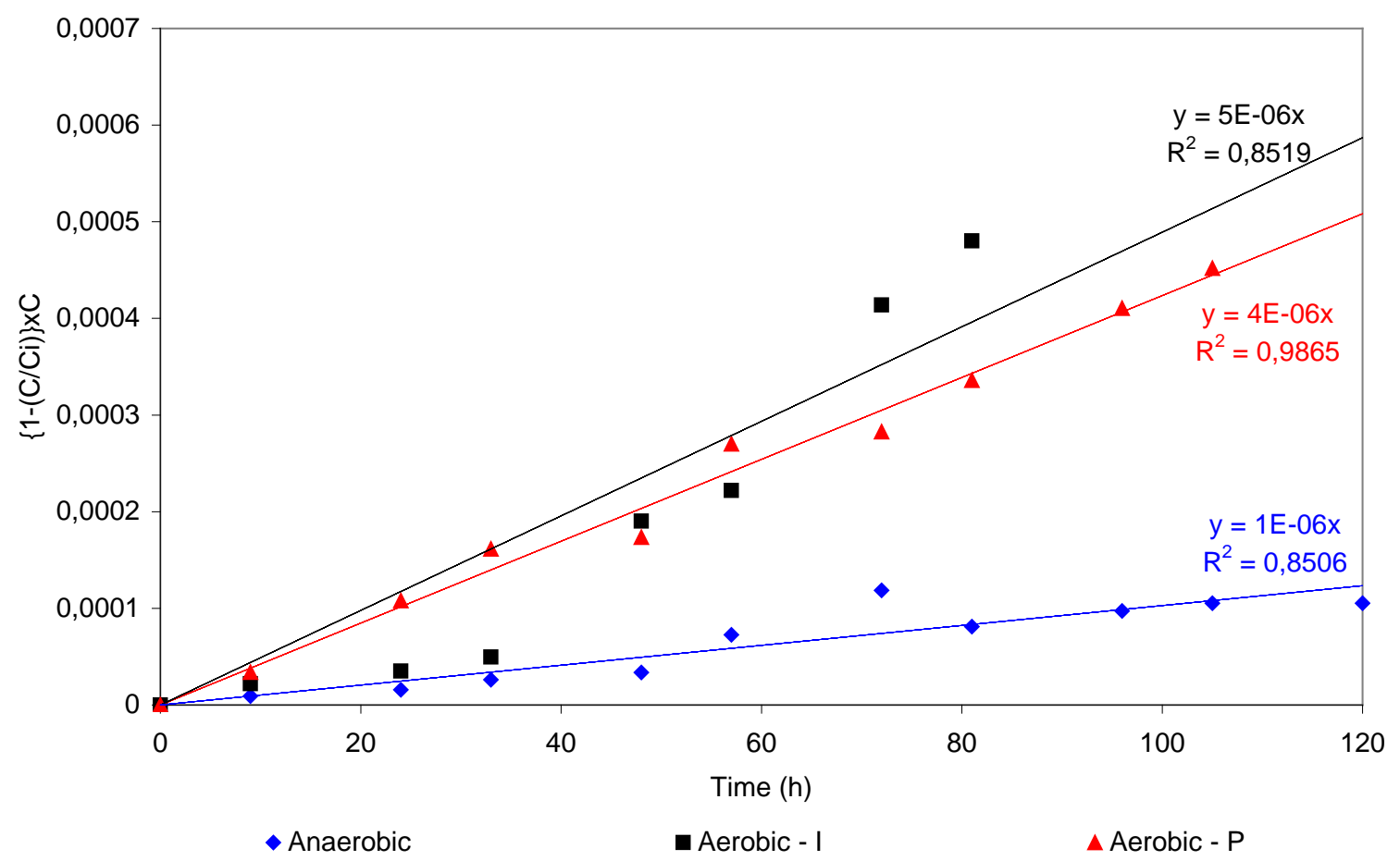

Figura 7: Ajuste linear de uma equação de segunda ordem para a cinética de degradação da Demanda Química de Oxigênio (DQO) do efluente, inoculado com a cepa específica de (GORDURAKLIN ${ }^{\circledR}$ ), ao longo do processo de biodegradação, em diferentes condições operacionais, frente à disponibilidade de oxigênio e efeitos hidrodinâmicos.

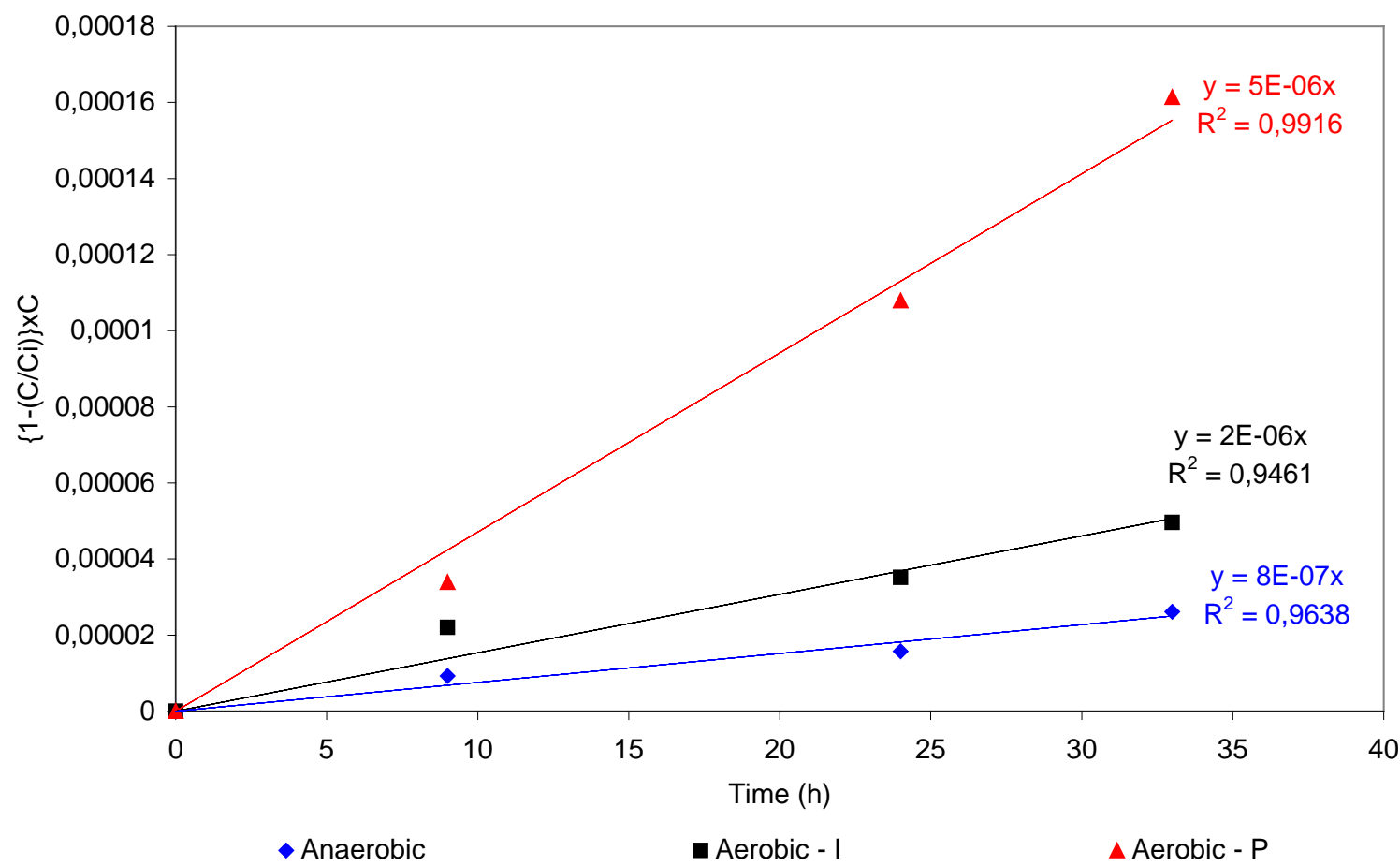

Figura 8: Ajuste linear de uma equação de segunda ordem para a cinética de degradação da Demanda Química de Oxigênio (DQO) do efluente, inoculado com a cepa específica de (GORDURAKLIN ${ }^{\circledR}$ ), nas primeiras horas de biodegradação, em diferentes condições operacionais, frente à disponibilidade de oxigênio e efeitos hidrodinâmicos. 


\section{CONCLUSÕES}

A partir dos resultados obtidos têm-se as seguintes considerações finais:

O processo de digestão anaeróbia, principal forma de aplicação comercial do Gorduraklin ${ }^{\circledR}$ em fossas e caixas de gorduras de esgotos sanitários, não é a técnica mais adequada para o emprego desse aditivo no tratamento dos efluentes do beneficiamento da castanha de caju, para degradação do liquido da castanha de caju (LCC).

A aplicação da técnica aeróbia com agitação demonstrou-se mais viável, com remoção da DQO do meio a níveis superiores a $80 \%$. Porém, estudos complementares se fazem necessários para aperfeiçoar tais condições operacionais, principalmente, para ajustar a relação substrato e matéria viva (bem como, parâmetros de aeração, tempo de residência e adensamento da população bacteriana em reatores adaptados para o tratamento em escala piloto).

Os indicadores utilizados para monitorar o meio reacional, tais como: $\mathrm{pH}$, acidez, alcalinidade e condutividade representaram o fluxo esperado para as reações previstas no ciclo reacional.

Estudos complementares são necessários para avaliar a composição dos subprodutos gerados e o efeito ecotoxicológico para lançamento desse efluente tratado em corpos d'água.

O uso da técnica aeróbica, com inserção do $\operatorname{GorduraKlin}^{\circledR}$, mostrou-se viável para o emprego no tratamento de efluentes oriundos do beneficiamento da castanha de caju com composição oleosa proveniente do liquido da castanha de caju, tendo-se uma aplicação prática para melhorar o desempenho das estações de tratamento desse segmento industrial com uso de um produto já comercializado e com custo compatível ao porte das indústrias desse segmento industrial.

\section{NOMENCLATURA}

C - Nível de DQO ao longo dos experimentos

Ci - Nível de DQO no início dos experimentos

DQO - Demanda química de oxigênio

LCC - Líquido da castanha de caju

NTU - Unidade nefelométrica de turbidez.

pH - Potencial hidrogeniônico

SF - Concentração de sólidos fixos no efluente
SS - Concentração de sólidos suspensos no efluente

ST - Concentração de sólidos totais no efluente

SV - Concentração de sólidos voláteis no efluente

T - Nível de Turbidez ao longo dos experimentos

Ti - Nível de Turbidez no início dos experimentos

\section{REFERÊNCIAS BIBLIOGRÁFICAS}


1. ALBUQUERQUE, A F, Biodegradação de compostos fenólicos em areia de moldagem utilizando microrganismos do solo. Campinas. FEC/Unicamp, 2000. 118 p. dissertação, Mestrado.

2. APHA, AWWA, WPCF. Standard Methods for Examination for Water and Wastewater. New York: 20th ed., 1998.

3. BRACELPA. Associação Brasileira de Celulose e Papel. Fax Notícias. ano VII, no 306, 2000.

4. BRAILE, P. M. \& CAVALCANTI, J. E. W. A Manual de tratamento de águas residuárias industriais. CETESB/São Paulo. 1993. 764 p.

5. CLAUSS, F.; BELAVOINE, C.; HELAINE, D. \& MARTIN, G. Controlling the settling of activated sludge in pulp and paper wastewater treatment plants. Water Science and technology. 40(1112): 223-229, 1999.

6. DORS, G. (2006). Hidrólise enzimática e biodigestão de efluentes da indústria de produtos avícolas. Dissertação de Mestrado, Universidade Federal de Santa Catarina, UFSC, Florianópolis, SC, Brasil. 101p.

7. FOSTER, M. H. \& WHITEMAN, G. R. Bioaugmentation aids wastewater systems. URL: http//www.bioaugmentation.com/article.html. Consultado em 23/set/1998.

8. JONES, C. M. A bioaumentação pode ajudar os sistemas de tratamento de efluentes. Disponível em: <http://tratamentoe.com.br/Efluentes.pdf>. Acesso em 08/07/2012.

9. LAZZARETTI, E. Utilização de microrganismos em estações de tratamento de efluentes bioaumento: uma opção para plantas de lodo ativado. Revista Meioa Ambiente Industrial, 18 (17): 81-83, 1999.

10. SANTIAGO, V. M. J.; COELHO, E. B. A; ALMEIDA, J. H. C. \& SANTANNA, L. M. M. O biodisco como gerador de inoculo de bactérias nitrificantes e sua aplicação em lagoas aeradas. Anais Simpósio Luso-Brasileiro de Engenharia Sanitária e Ambiental, 9., Porto Seguro-BA, 2000

11. SOARES, H. M. \& ZAIAT, M. (2005). Processos anaeróbios de tratamento de matéria orgânica. In: $V$ Curso de Tratamento Biológico de Resíduos. Florianópolis/SC. Projeto PROSUL/CNPq UFSC/UDELAR/UNLP, cap. V.2, 37p.

12. VON SPERLING, M.. Introdução à qualidade das águas e ao tratamento de esgotos. 3 ed. Belo Horizonte: Departamento de Engenharia Sanitária e Ambiental; Universidade Federal de Minas Gerais; 2005.

13. VON SPERLING, M.. Lagoas de Estabilização. 2 ed. Belo Horizonte: Departamento de Engenharia Sanitária e Ambiental; Universidade Federal de Minas Gerais; 2002.

14. WATER ENVIRONMENT FEDERATION. Wastewater biology: the life processes. GERARDI, M. H. coord. Library of Congresss. Catalog no ISBNI 881369-93-5, USA. 1994. 184 p.

15. WORLD HEALTH ORGANIZATION. Health guidelines for the use of wastewater in agriculture and aquaculture. Technical report series. 778. Geneva: World Health and Organization, 72p. 1989.

16. ZANOTTO, S. P. (2003). Utilização de enzimas e microrganismos para a obtenção de compostos oticamente ativos. Tese de Doutorado, Universidade Federal de Santa Catarina, UFSC, Florianópolis, SC, Brasil. 123p. 